\title{
IMPACT OF THE ADDITION OF BARLEY FLOUR ON INDICATORS OF BREAD FROM A MIXTURE OF WHITE WHEAT AND RYE FLOUR
}

\author{
Tatjana Pavlova ${ }^{1}$, Zlatin Zlatev ${ }^{2}$ \\ ${ }^{1}$ Faculty of Technological and Technical Sciences, \\ Saint Kliment Ohridski University of Bitola, \\ Dimitar Vlahov bb str., 1400 Veles, Republic of North Macedonia \\ e-mail: tatjanapavlova15@yahoo.com \\ ${ }^{2}$ Faculty of Technics and Technologies of Yambol \\ Trakia University of Stara Zagora \\ 38 Graf Ignatiev str., 8602 Yambol, Bulgaria \\ e-mail: zlatin.zlatev@trakia-uni.bg
}

\begin{abstract}
The influence of the addition of barley flour on indicators of bread from a mixture of white wheat and rye flour was tested. It has been found that the ratio of $30 \%$ white wheat and $70 \%$ rye flour is suitable for a control sample to which barley flour is added, because at this ratio there are high values of the conductivity indicators, Total dissolved solids, Oxidation-reduction potential, and the $\mathrm{pH}$ is neutral. It has been shown that the $30 \%$ added barley flour to a mixture of wheat and rye flour has no significant influence on the appearance and color of the bread and improves its organoleptic characteristics. The results of the study show that good results are obtained in studies based on VIS spectral data because the major part of the properties tested for flour, dough and bread are visible properties that can be analyzed in the visible spectrum of the reflected light. Spectral indexes obtained in the $620 \mathrm{~nm}$ range were found to be a suitable tool for the analysis of rye-wheat bread with added barley flour.
\end{abstract}

Keywords: White wheat flour, rye, barley, sensory analysis, color, spectral characteristics, spectral indices.

\section{INTRODUCTION}

The use of flour mixes increases the range of bread and bakery products [4]. The large number of potentially active nutrients and their multifunctional properties make the barley (Hordeum vulgare) a functional component for the production of healthy food products and food supplements $[8,19]$. Rye flour is characterized by a relatively high content of calcium, potassium, sodium and low copper, zinc and iron [10].

The use of barley in bakery blends explores Stoeva [16]. According to the author, nontraditional use of barley rich in $\beta$-glucan in wheat mixtures for bakery purposes is a health concern. In this sense, a suitable mixture to achieve a higher amount of $\beta$-glucan is $50 \%$ wheat $-50 \%$ barley. It states that the presence of barley in various mixtures with wheat leads to a reduction in their technological and baking characteristics, the degree of reduction being dependent on the quality status of the varieties used and the proportion of barley in the mixtures.

According to Bastin [2], the use of various flours will result in a varied appearance, taste and nutritional value of bread and bakery products. The author points out that barley adds malt flavor to bread. She recommends using 1 part barley to 3 parts wheat flour.

Mihalkova et al. [9] investigate mixtures of various flours, including white wheat, rye and barley. The authors offer bread making technology from this blend. The addition of barley flour is $10 \%$.

IRTIIE Vol. 7, No. 1, 2019 ISSN 1314-8788 (print), ISSN 1314-8796 (online), doi: 10.15547/artte.2019.01.004 


\section{ARTTIE $Y$}

Ipplied Resseirlores in Technics, Technologies and Educration

Journal of the Faculty of Technics and Technologies, Trakia University https://sites.google.com/a/trakia-uni.bg/artte/

Kalnina et al. [6] investigated blends of white wheat, rye and barley flour during paste preparation. Flour of barley has been added 10, 20,30,40,50\% to white wheat flour. The results for a mixture of white wheat and whole wheat wheat in a ratio of $50 / 50 \%$ were reported. The authors did not report mixing results from the three flours at the same time.

From the analysis of available literature sources, it has been found that there are few publications in which a mixture of white wheat, rye and barley flour is studied. It is necessary to define criteria for determining a control sample of white wheat and rye flour to which barley flour is to be added. There is not a large number of studies related to the color change of flour, dough and bread obtained from these mixtures, and as is known, color is one of the main indicators by which the consumer accepts or rejects a product $[3,7,11]$.

The aim of the article is to analyze the influence of barley flour on the indicators of a mixture of white wheat and rye flour.

\section{MATERIAL AND METHODS}

Mixed wheat flour mixtures of type 500 (Topaz Mel Ltd., Bulgaria), flour type 1750 rye (ET TIT-Tenko Tenev, Kameno, Bulgaria) were purchased from the commercially, whole wheat flour from barley (Ecosm Bulgaria Ltd, Stambolovo, Bulgaria).

The bread is made of mixtures of wheat, rye and barley flour. The main technology used is that laid down in an approved white bread standard AS02/2011 [1]. The dough is prepared by a single-phase method with one mixing during rising. Yeast Evmaya (Mauri Maya Sanayi AS, Aksakal Bandirma Turkiye) was used; drinking water, according to Ordinance No. 9 of 16.03.2001 [12]; iodized salt, according to Decree of the Council of Ministers No 23/2001 [13].

The quantity of raw materials was determined with a Pocket Scale MH-200 (ZheZhong Weighing Apparatus Factory), a maximum determined mass of $200 \mathrm{~g}$, with a resolution of $0.02 \mathrm{~g}$.

\subsection{Parameters of Raw Materials, Dough and Bread}

The flour mixtures were measured:

- Conductivity EC, $\mu \mathrm{S} / \mathrm{cm}$, Conductivity Meter AP-2 (HM Digital, Inc);

- Active acidity pH, pH meter PH-108 (Hangzhou Lohand Biological Co., Ltd);

- Total Dissolved Solids TDS, ppm, TDS-3 measuring instrument (HM Digital, Inc.);

- Oxidation Reduction Potential ORP, mV, Measuring Instrument Model ORP-2069 (Shanghai Longway Optical Instruments Co., Ltd).

Measurements were made at room temperature of $20 \pm 2^{\circ} \mathrm{C}$ and relative humidity of $45 \% \mathrm{RH}$. The preparation of the measurement samples is made according to the methodology presented in [14]: distilled water is heated to $70^{\circ} \mathrm{C}$; the raw material (flour, dough, bread) is dissolved in the distilled water in a ratio of $1 / 10$ ( $5 \mathrm{~g}$ of raw material in $50 \mathrm{ml}$ of distilled water); stirring until a homogeneous solution is obtained; after cooling to ambient room temperature, three consecutive measurements of each indicator were made and their average value was determined.

Data are processed at a level of significance $\alpha=0.05$.

\subsection{Bread Sensory Analysis}

The resulting bread is cooled for 3 hours at room temperature $\left(20-22^{\circ} \mathrm{C}\right)$. It is then cut into pieces $2 \times 3 \times 5 \mathrm{~cm}$. The sensory evaluation was carried out with 15 respondents from the faculty of Technics and Technology, Yambol, Bulgaria. Bread has been evaluated for

IRTIIE Vol. 7, No. 1, 2019 ISSN 1314-8788 (print), ISSN 1314-8796 (online), doi: 10.15547/artte.2019.01.004 


\section{ART'TE $Y$}

Ipplied Resseirlohes in Technics, Technologies and Eductition Journal of the Faculty of Technics and Technologies, Trakia University https://sites.google.com/a/trakia-uni.bg/artte/

compliance with the organoleptic characteristics set out in AS02/2011. A 9-level scale is used: 1 - does not fully match, 9 - has full compliance with the benchmark as stated in the approved standard.

\subsection{Capturing and Processing of Digital Images}

The digital images are obtained with GTC 903 video camera, equipped with an IR filter and captured images in the visible (VIS) spectrum of light (390-780nm).

When processing images, it is necessary to cut only the middle part of the image first and the new image thus obtained is used in the computerized analysis programs. This is done in order to avoid the influence of the background, the cake of the product, and the color of the crust in the bread because they will influence the color and spectral characteristics of the products.

\subsection{Color Components}

The color components of the RGB color model (RGB [0255]) were converted to Lab ( $\mathrm{L}$ [0 100], a [-86.18 98.23], b [-107.86 94.47]).

\subsection{Spectral Characteristics}

The Color Matching Function CIE 1931, with observer $2^{\circ}$, is used for illumination D65 (representing average daylight with UV component, 6500K). The transformation of $X Y Z$ model values into reflection spectra in the VIS area, in the range $390-730 \mathrm{~nm}$, is done by mathematical dependencies, and the conversion is possible in both directions of equality [5, 17].

Mathematical dependencies for conversion from RGB to spectra in the visible spectral region are:

$$
\begin{aligned}
& X Y Z=R G B \cdot M_{X Y Z} \\
& M_{X Y Z}=\left[\begin{array}{lll}
0,5767 & 0,2974 & 0,027 \\
0,1855 & 0,6273 & 0,0707 \\
0,1882 & 0,0753 & 0,9911
\end{array}\right] \\
& X=\int_{380}^{780} A(\lambda) \bar{X}(\lambda) d \lambda ; Y=\int_{380}^{780} A(\lambda) \bar{Y}(\lambda) d \lambda ; Z=\int_{380}^{780} A(\lambda) \bar{Z}(\lambda) d \lambda \\
& \Delta E_{V I S}=\sqrt{\Delta X^{2}+\Delta Y^{2}+\Delta Z^{2}}
\end{aligned}
$$

where $M$ is a matrix for transformation under the specified observer and illumination conditions. A $(\lambda)$ is a matrix for color transformation to reflectance spectra in VIS areas, according to observer used and illumination. These matrices are available in [15] for the VIS spectral region. The difference between the different components is used.

The obtained digital images and spectral characteristics in the VIS spectral region are presented in Appendix 1.

Spectral indexes. Spectral indices are used which are more commonly used in plant analysis [18].

IRTIIE Vol. 7, No. 1, 2019 ISSN 1314-8788 (print), ISSN 1314-8796 (online), doi: 10.15547/artte.2019.01.004 


\section{IRTTL $\vee$}

$$
S I=\frac{R_{\text {crumb }}-R_{\text {crust }}}{R_{\text {crumb }}+R_{\text {crust }}}
$$

where $R_{\text {crumb }}$ is the reflection of the bread crumb; $R_{\text {crust }}$ - a reflection of the crust. Reflections are measured in three wavelengths of 420,520 and $620 \mathrm{~nm}$.

\section{RESULTS AND DISCUSSION}

The measured indicators of a mixture of white wheat and rye flour are presented in Figure 1. The dependence of these parameters on the amount of rye flour added to the mixture is shown. It is seen that when adding $70 \%$ rye flour, maximum EC, TDS and ORP values are obtained. The active acidity is $\mathrm{pH}=7.0$, indicating that it is neutral.

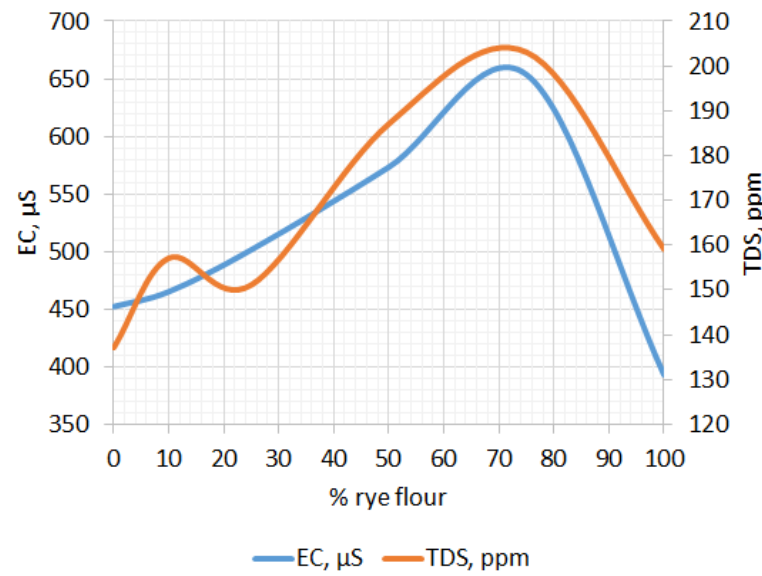

a) Electrical conductivity (EC) and Totally dissolved solids (TDS)



b) Active acidity $(\mathrm{pH})$ and Oxidation/reduction potential (ORP)

Figure 1. Measured parameters of flour mixtures of white wheat and rye flour

Mixing of flour has little impact on the measured EC, $\mathrm{pH}$, ORP parameters. There are differences in the TDS parameter. Impact on these parameters would be the fermentation processes involved in doughing (for example, in rising and proofing) with the ratio between rye and wheat flour.

A control sample of $30 \%$ white wheat and $70 \%$ rye flour was determined.

The measured indicators of a mixture of white wheat, rye flour in a ratio of $30 / 70 \%$ and barley flour $0-100 \%$ are presented in Figure 2. The dependence of these parameters on the amount of barley flour added to the mixture is shown. It is seen that when adding $30 \%$ of barley flour, minimal EC, TDS and ORP values are obtained.

Upon addition of $50 \%$ barley flour, a change in the direction of the characteristics is observed leading to the determination of their values. The active acidity of a $30 \%$ barley flour is $\mathrm{pH}=$ 7.3 , indicating that it is alkaline. 


\section{IR'TIE}

Ipplied Reserer rhes in Technics, Technologies and Bduration Journal of the Faculty of Technics and Technologies, Trakia University https://sites.google.com/a/trakia-uni.bg/artte/

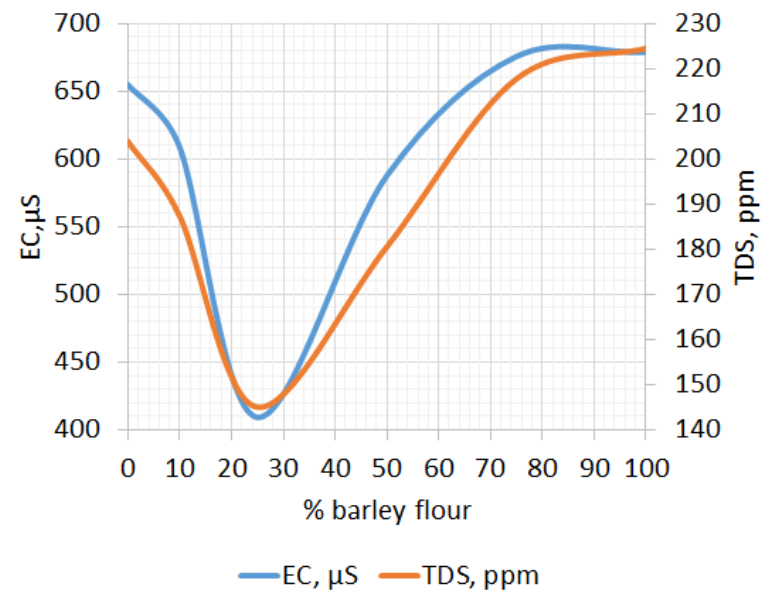

a) Electrical conductivity (EC) and Totally dissolved solids (TDS)



$-\mathrm{pH}-\mathrm{ORP}, \mathrm{mV}$

b) Active acidity $(\mathrm{pH})$ and

Oxidation/reduction potential (ORP)

Figure 2. Measured parameters of flour mixtures of white wheat, rye and barley flour

The control sample of white wheat and rye flour is mixed with $30 \%$ and $50 \%$ barley flour. Tables 1, 2 and 3 provide results for the measured technological indicators of the samples of flour mixtures with wheat, rye and barley flour, dough and bread produced from them. It can be seen that the addition of barley flour increases the $\mathrm{pH}$ of the mixture to $\mathrm{pH}=7.1-7.3$. The addition of $50 \%$ barley flour to the mixture increases electrical conductivity and oxidationreduction potential. When the dough is mixed with the selected mixtures, an increase in the conductivity and the oxidation-reduction potential is observed while the $\mathrm{pH}$ decreases, an sour taste of the dough is observed. The resulting bread retains high conductivity and oxidation-reduction potential as $\mathrm{pH}$ increases and approaches flour values.

Table 1. Parameters of mixtures of wheat, rye and barley flour

\begin{tabular}{|c|c|r|r|r|r|r|}
\hline Wheat flour, $\%$ & Rye flour, $\%$ & Barley flour, $\%$ & EC, $\boldsymbol{\mu S}$ & \multicolumn{1}{|c|}{ TDS, $\mathbf{p p m}$} & \multicolumn{1}{c|}{$\mathbf{p H}$} & ORP, $\mathbf{~ m V}$ \\
\hline $\mathbf{1 0 0}$ & $\mathbf{0}$ & $\mathbf{0}$ & 452 & 137 & 7,3 & 139 \\
\hline $\mathbf{3 0}$ & $\mathbf{7 0}$ & $\mathbf{0}$ & 655 & 204 & 7,0 & 152 \\
\hline $\mathbf{2 5}$ & $\mathbf{4 5}$ & $\mathbf{3 0}$ & 410 & 145 & 7,3 & 143 \\
\hline $\mathbf{2 0}$ & $\mathbf{3 0}$ & $\mathbf{5 0}$ & 588 & 181 & 7,1 & 159 \\
\hline
\end{tabular}

Table 2. Parameters of dough form mixtures of wheat, rye and barley flour

\begin{tabular}{|c|c|c|r|r|r|r|}
\hline Wheat flour, \% & Rye flour, \% & Barley flour, \% & EC, $\boldsymbol{\mu S}$ & \multicolumn{1}{|c|}{ TDS, $\mathbf{p p m}$} & \multicolumn{1}{c|}{ pH } & ORP, $\mathbf{~} \mathbf{V}$ \\
\hline $\mathbf{1 0 0}$ & $\mathbf{0}$ & $\mathbf{0}$ & 825 & 215 & 6,9 & 196 \\
\hline $\mathbf{3 0}$ & $\mathbf{7 0}$ & $\mathbf{0}$ & 1288 & 284 & 6,9 & 199 \\
\hline $\mathbf{2 5}$ & $\mathbf{4 5}$ & $\mathbf{3 0}$ & 1326 & 272 & 6,8 & 207 \\
\hline $\mathbf{2 0}$ & $\mathbf{3 0}$ & $\mathbf{5 0}$ & 1300 & 313 & 6,8 & 203 \\
\hline
\end{tabular}

Table 3. Parameters of bread with mixtures of wheat, rye and barley flour

\begin{tabular}{|c|c|c|r|r|r|r|}
\hline Wheat flour, \% & Rye flour, \% & Barley flour, \% & EC, $\boldsymbol{\mu S}$ & TDS, $\mathbf{p p m}$ & \multicolumn{1}{|c|}{ pH } & ORP, $\mathbf{~} \mathbf{V}$ \\
\hline $\mathbf{1 0 0}$ & $\mathbf{0}$ & $\mathbf{0}$ & 739 & 204 & 7,7 & 192 \\
\hline $\mathbf{3 0}$ & $\mathbf{7 0}$ & $\mathbf{0}$ & 1256 & 270 & 7,2 & 205 \\
\hline $\mathbf{2 5}$ & $\mathbf{4 5}$ & $\mathbf{3 0}$ & 1066 & 257 & 7,2 & 207 \\
\hline $\mathbf{2 0}$ & $\mathbf{3 0}$ & $\mathbf{5 0}$ & 1263 & 293 & 7,2 & 212 \\
\hline
\end{tabular}


Differences in the color characteristics of white wheat and rye flour were determined by the Lab color model. Table 4 shows that the $\mathrm{L}$ and $\mathrm{b}$ color components have a significant difference while the component is virtually unchanged.

Table 4. Mean, standard deviation and coefficient of variation for Lab color model of white wheat and rye flour

\begin{tabular}{|c|c|c|c|c|c|c|c|c|c|c|c|c|c|c|c|c|c|c|}
\hline Sample & \multicolumn{3}{|c|}{$100 \mathrm{~W}$} & \multicolumn{3}{|c|}{$90 W+10 R$} & \multicolumn{3}{|c|}{$75 W+25 R$} & \multicolumn{3}{|c|}{$50 \mathrm{~W}+50 \mathrm{R}$} & \multicolumn{3}{|c|}{$25 W+75 R$} & \multicolumn{3}{|c|}{ 100R } \\
\hline DS & mean & SD & CV & mean & SD & $\mathrm{CV}$ & mean & SD & CV & mean & SD & CV & mean & SD & CV & mean & SD & CV \\
\hline$L$ & 74,62 & 3,83 & 0,05 & 72,65 & 4,59 & 0,06 & 73,43 & 4,05 & 0,06 & 71,11 & 3,99 & 0,06 & 70,96 & 3,80 & 0,05 & 80,48 & 3,22 & 0,04 \\
\hline a & 2,40 & 1,27 & 0,53 & 2,41 & 1,08 & 0,45 & 2,29 & 1,72 & 0,75 & 3,63 & 1,21 & 0,33 & 3,67 & 1,44 & 0,39 & 2,73 & 0,70 & 0,26 \\
\hline b & 3,03 & 2,78 & 0,92 & 0,52 & 1,92 & 3,69 & 3,06 & 2,45 & 0,80 & 1,62 & 2,60 & 1,60 & 1,67 & 2,19 & 1,32 & 2,16 & 0,96 & 0,44 \\
\hline
\end{tabular}

The addition of barley flour leads to a change in the a color component. This additive results in the other two components $L$ and $b$ being identified. The results of measuring the color of $a$ mixture of white wheat, rye and barley flour are presented in Table 5.

Table 5. Mean, standard deviation and coefficient of variation for Lab color model of white wheat, rye and barley flour

\begin{tabular}{|c|r|r|r|r|r|r|r|r|r|r|r|r|r|r|r|r|r|r|r|}
\hline Sample & \multicolumn{3}{|c|}{$30 \mathrm{~W}+\mathbf{7 0 R}$} & \multicolumn{2}{|c|}{ 27W+63R+10B } & \multicolumn{2}{|c|}{ 25W+45R+25B } & \multicolumn{2}{|c|}{ 20W+30R+50B } & \multicolumn{3}{|c|}{$\mathbf{8 W + 1 8 R + 7 5 B}$} & \multicolumn{1}{|c|}{ 100B } \\
\hline CC DS & mean & SD & CV & mean & SD & CV & mean & SD & CV & mean & SD & CV & mean & SD & CV & mean & SD & CV \\
\hline L & $\mathbf{6 7 , 0 6}$ & 5,40 & 0,08 & $\mathbf{6 4 , 2 6}$ & 5,54 & 0,09 & $\mathbf{6 4 , 9 4}$ & 5,56 & 0,09 & $\mathbf{6 6 , 6 9}$ & 5,73 & 0,09 & $\mathbf{6 7 , 3 6}$ & 4,63 & 0,07 & $\mathbf{7 0 , 1 3}$ & 4,90 & 0,07 \\
\hline a & $-\mathbf{0 , 3 9}$ & 0,55 & $-1,39$ & $\mathbf{0 , 3 5}$ & 0,67 & 1,89 & $\mathbf{1 , 7 4}$ & 0,56 & 0,32 & $\mathbf{4 , 0 5}$ & 0,70 & 0,17 & $\mathbf{0 , 0 0}$ & 0,53 & 140,4 & $\mathbf{0 , 6 0}$ & 0,52 & 0,87 \\
\hline b & $\mathbf{3 , 6 7}$ & 1,32 & 0,36 & $\mathbf{3 , 0 2}$ & 0,55 & 0,18 & $\mathbf{1 , 4 5}$ & 0,72 & 0,49 & $-\mathbf{- 0 , 6 7}$ & 0,84 & $-1,25$ & $\mathbf{5 , 8 7}$ & 0,69 & 0,12 & $\mathbf{3 , 2 5}$ & 0,86 & 0,26 \\
\hline
\end{tabular}

DS-descriptive statistics; CC-color component; W-percentage wheat flour; R-percentage rye flour; Bpercentage barley flour; mean-arithmetic mean; SD-standard deviation; CV-coefficient of variation

Table 6 shows the color measurements of dough obtained from a mixture of white wheat, rye and barley flour. In the dough after rising process, changes only in the a color component is observed again. $L$ and $b$ components remain constant, irrespective of the added amount of barley flour.

Table 6. Mean, standard deviation and coefficient of variation for Lab color model of a mixture of white wheat, rye and barley flour

\begin{tabular}{|c|r|r|r|r|r|r|r|r|r|r|r|r|}
\hline Sample & \multicolumn{3}{|c|}{ 100W } & \multicolumn{3}{|c|}{$\mathbf{3 0 W + 7 0 R}$} & \multicolumn{3}{|c|}{ 25W+45R+30B } & \multicolumn{3}{|c|}{ 20W+30R+50B } \\
\hline CC DS & mean & SD & CV & mean & SD & CV & mean & SD & CV & mean & SD & CV \\
\hline L & $\mathbf{7 7 , 0 0}$ & 5,96 & 0,08 & $\mathbf{7 7 , 3 5}$ & 7,40 & 0,10 & $\mathbf{7 7 , 9 1}$ & 5,79 & 0,07 & $\mathbf{7 6 , 2 9}$ & 7,94 & 0,10 \\
\hline a & $\mathbf{- 3 , 2 2}$ & 0,90 & $-0,28$ & $\mathbf{5 , 5 3}$ & 1,57 & 0,28 & $\mathbf{3 , 8 2}$ & 0,79 & 0,21 & $\mathbf{3 , 6 5}$ & 0,74 & 0,20 \\
\hline b & $\mathbf{2 3 , 0 6}$ & 1,49 & 0,06 & $\mathbf{2 2 , 8 5}$ & 0,91 & 0,04 & $\mathbf{2 2 , 5 3}$ & 0,85 & 0,04 & $\mathbf{2 2 , 2 3}$ & 0,54 & 0,02 \\
\hline
\end{tabular}

DS-descriptive statistics; CC-color component; W-percentage wheat flour; R-percentage rye flour; Bpercentage barley flour; mean-arithmetic mean; SD-standard deviation; CV-coefficient of variation

Figure 3 shows the bread samples obtained. Bread with $100 \%$ wheat flour is obtained with the largest volume $\left(\mathrm{V}, \mathrm{cm}^{3}\right)$ compared to other samples, it has a well-developed porosity and larger bumps to the upper crust. Increasing the amount of barley flour worsens the characteristics of the bread - it does not develop well and results in a small volume and height. 


\section{IRTIIE}

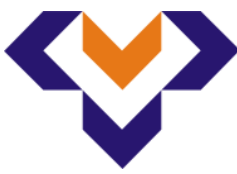

Ipplied Resseirlohes in Technics, Technologies and Eductition

Journal of the Faculty of Technics and Technologies, Trakia University https:///ites.google.com/a/trakia-uni.bg/artte/

The control sample with $30 \%$ wheat and $70 \%$ rye flour has a bright brownish color, with a slight cracking of the upper crust. The color of the crumb is uniform, brownish. The porosity is small, developed and even. Bread has a pleasant aroma. The taste is pleasant, typical of the type.

The sample of $30 \%$ barley flour has slight cracks in the upper crust and a slightly thicker upper crust. The color of the crumb is brownish. The crumb is more developed, the porosity is thicker than the control. The aroma is pleasant and slightly compassionate. The taste is pleasant, slightly sour.

The sample of $50 \%$ barley flour has tears on the top surface. The color of the crumb is brownish, pale than the control sample. The thickness of the crust is thicker than the control. The color of the crumb is darker brown. The porosity is not well developed compared to the other two samples. The flavor is characteristic of the ingredients. The taste is sour.

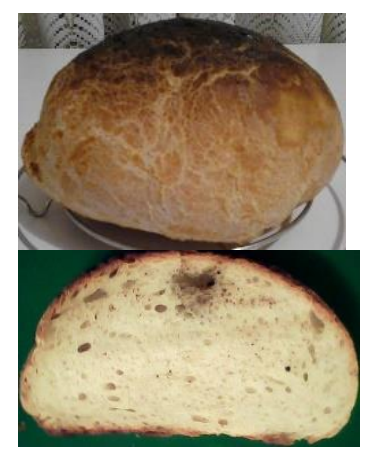

$100 \%$ wheat

$\mathrm{V}=1047 \mathrm{~cm}^{3}$

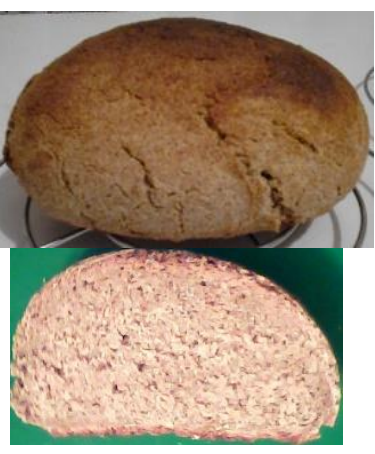

$30 \%$ wheat $+70 \%$ rye $\mathrm{V}=585 \mathrm{~cm}^{3}$

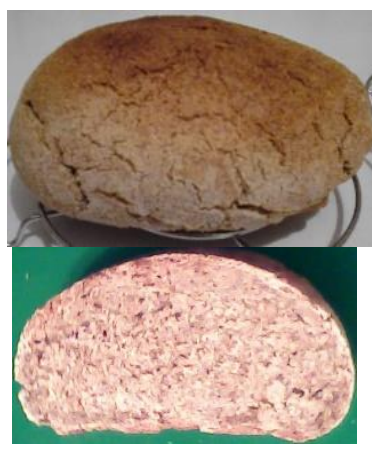

$25 \%$ wheat $+45 \%$ rye $+30 \%$ barley $\mathrm{V}=541 \mathrm{~cm}^{3}$

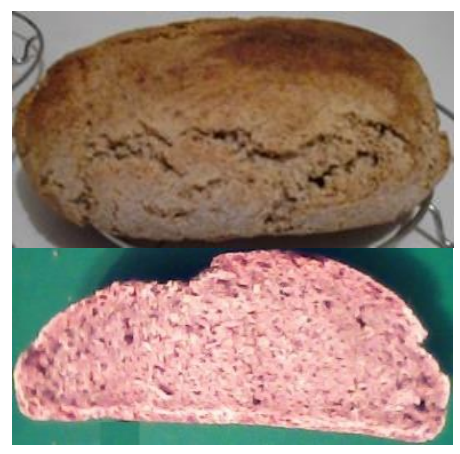

$20 \%$ wheat $+30 \%$ rye + $50 \%$ barley $\mathrm{V}=520 \mathrm{~cm}^{3}$

Figure 3. Bread obtained with mixtures of white wheat, rye and barley flour

Tables 7 and 8 give the color components of the Lab color model for the crumb and the crust of the obtained bread. It can be seen that $L$ and a color components have no significant difference between the crumb and the crust. A difference is observed for the $b$ component, where it is more than 10 units.

Table 7. Mean, standard deviation and coefficient of variation for Lab color model of bread crumb

\begin{tabular}{|c|r|c|r|r|r|r|r|r|r|r|r|r|}
\hline Sample & \multicolumn{4}{|c|}{ 100W } & \multicolumn{3}{|c|}{ 30W+70R } & \multicolumn{2}{|c|}{ 25W+45R+30B } & \multicolumn{2}{|c|}{ 20W+30R+50B } \\
\hline CC DS & mean & SD & CV & mean & SD & CV & mean & SD & CV & mean & SD & CV \\
\hline L & $\mathbf{7 6 , 4 6}$ & 5,58 & 0,07 & $\mathbf{7 7 , 7 7}$ & 5,85 & 0,08 & $\mathbf{7 5 , 6 2}$ & 6,49 & 0,09 & $\mathbf{7 7 , 2 8}$ & 6,53 & 0,08 \\
\hline a & $\mathbf{- 2 , 2 6}$ & 1,05 & $-0,46$ & $\mathbf{8 , 3 4}$ & 0,69 & 0,08 & $\mathbf{8 , 3 8}$ & 1,21 & 0,14 & $\mathbf{8 , 4 2}$ & 0,86 & 0,10 \\
\hline b & $\mathbf{2 5 , 0 3}$ & 0,73 & 0,03 & $\mathbf{2 0 , 4 0}$ & 0,77 & 0,04 & $\mathbf{2 0 , 5 3}$ & 0,76 & 0,04 & $\mathbf{1 9 , 1 7}$ & 0,84 & 0,04 \\
\hline
\end{tabular}

DS-descriptive statistics; CC-color component; W-percentage wheat flour; R-percentage rye flour; Bpercentage barley flour; mean-arithmetic mean; SD-standard deviation; CV-coefficient of variation 


\section{IRITIE}

Ipplied Reserer rhes in Technics, Technologies and Bduration Journal of the Faculty of Technics and Technologies, Trakia University https://sites.google.com/a/trakia-uni.bg/artte/

Table 8. Mean, Standard Deviation and coefficient of variation for Lab Color Model of Bread crust

\begin{tabular}{|c|c|c|c|c|r|r|r|r|r|r|r|r|}
\hline Sample & \multicolumn{3}{|c|}{ 100W } & \multicolumn{3}{|c|}{ 30W+70R } & \multicolumn{3}{|c|}{ 25W+45R+30B } & \multicolumn{3}{|c|}{ 20W+30R+50B } \\
\hline CC DS & mean & SD & CV & mean & SD & CV & mean & SD & CV & mean & SD & CV \\
\hline L & $\mathbf{7 7 , 7 4}$ & 5,52 & 0,07 & $\mathbf{7 2 , 8 7}$ & 7,29 & 0,10 & $\mathbf{7 5 , 8 9}$ & 7,40 & 0,10 & $\mathbf{8 2 , 1 7}$ & 8,72 & 0,11 \\
\hline a & $\mathbf{2 7 , 1 9}$ & 7,04 & 0,26 & $\mathbf{3 4 , 2 0}$ & 10,61 & 0,31 & $\mathbf{2 6 , 9 3}$ & 6,10 & 0,23 & $\mathbf{1 8 , 1 9}$ & 6,06 & 0,33 \\
\hline b & $\mathbf{1 6 , 6 7}$ & 5,01 & 0,30 & $\mathbf{2 1 , 7 8}$ & 3,92 & 0,18 & $\mathbf{1 9 , 0 4}$ & 5,48 & 0,29 & $\mathbf{9 , 6 1}$ & 2,83 & 0,29 \\
\hline
\end{tabular}

DS-descriptive statistics; CC-color component; W-percentage wheat flour; R-percentage rye flour; Bpercentage barley flour; mean-arithmetic mean; SD-standard deviation; CV-coefficient of variation

An analysis by spectral indices on the influence of the added amount of barley flour on the color change of the bread was made. Figure 4 shows results for these indices. It can be seen that in the $620 \mathrm{~nm}$ spectral range, indices in the red region are informative and show the variation in the color of the bread depending on the added amount of barley flour. In the other analyzed ranges (420 and 520 $\mathrm{nm}$ ) the spectral indices did not show a significant change.

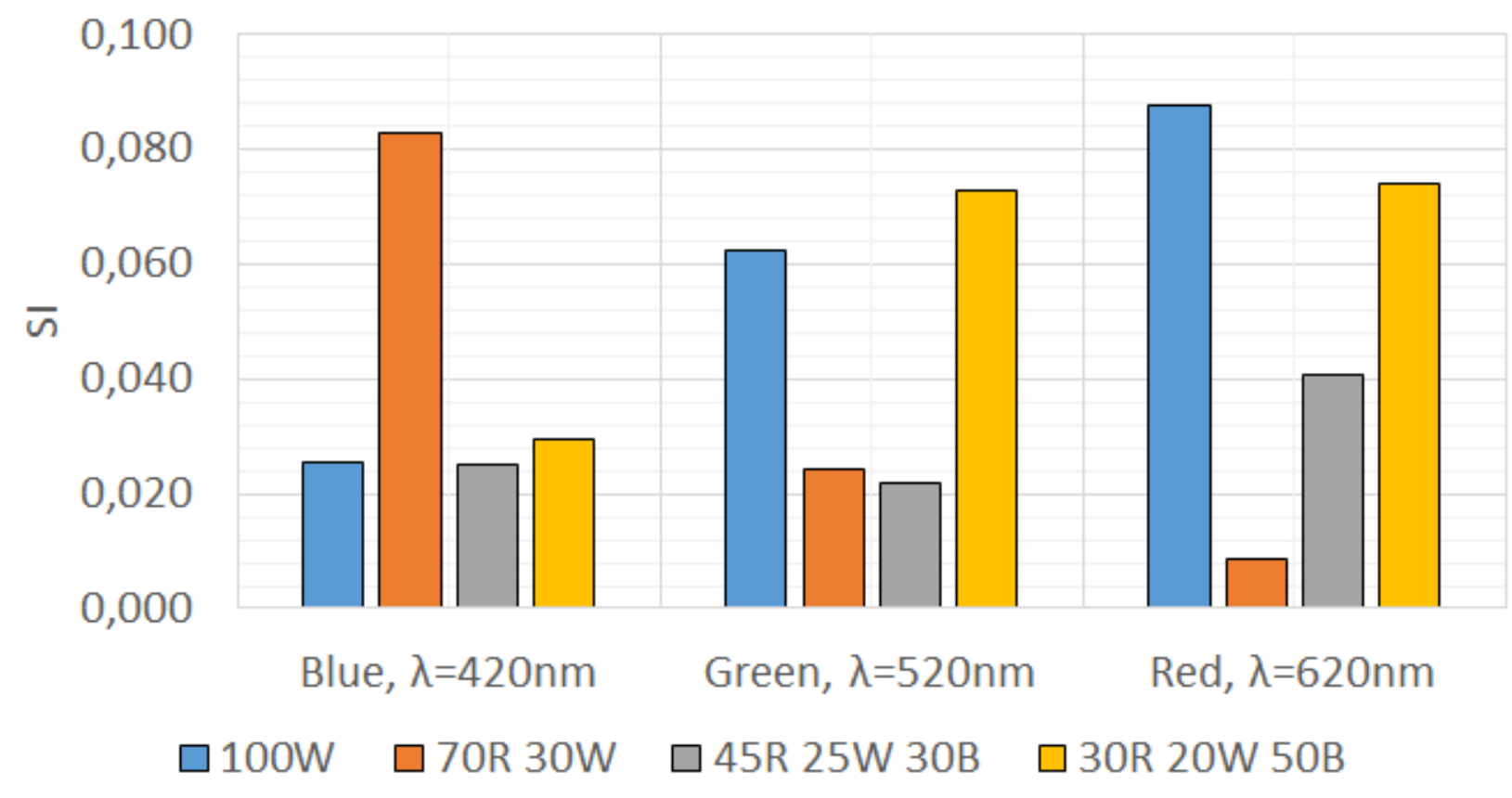

Figure 4. Spectral indices of bread

The results of organoleptic analysis of bread from a mixture of white wheat and rye flour with the addition of $30 \%$ and $50 \%$ barley flour are shown in Table 9 . There are similarities between the control sample without the addition of barley flour and the bread with $30 \%$. The high content of $50 \%$ of barley flour worsens the organoleptic characteristics of the bread obtained and consequently receives lower estimates compared to the other two types of bread. The addition of $50 \%$ barley flour improves the color of the bark and therefore gets the highest score on this indicator. 


 Journal of the Faculty of Technics and Technologies, Trakia University https://sites.google.com/a/trakia-uni.bg/artte/}

Table 9. Results of sensory analysis of bread with mixtures of wheat, rye and barley flour

\begin{tabular}{|c|c|c|c|c|c|c|c|c|c|}
\hline \multirow{2}{*}{ Indicator } & \multicolumn{3}{|c|}{$\begin{array}{c}30 \% \text { wheat }+70 \% \\
\text { rye }\end{array}$} & \multicolumn{3}{|c|}{$\begin{array}{c}25 \% \text { wheat }+45 \% \text { rye }+ \\
30 \% \text { barley }\end{array}$} & \multicolumn{3}{|c|}{$\begin{array}{c}20 \% \text { wheat }+30 \% \text { rye }+ \\
50 \% \text { barley }\end{array}$} \\
\hline & mean & SD & CV & mean & SD & CV & mean & SD & CV \\
\hline Crust color & 6,33 & 0,58 & 0,09 & 7,00 & 0,00 & 0,00 & 8,00 & 0,00 & 0,00 \\
\hline Taste & 6,67 & 0,58 & 0,09 & 7,67 & 0,58 & 0,08 & 6,33 & 0,58 & $0,0 \mathrm{~s}$ \\
\hline Texture & 7,67 & 0,58 & 0,08 & 7,33 & 1,15 & 0,16 & 5,67 & 0,58 & 0,10 \\
\hline Flavor & 7,67 & 1,15 & 0,15 & 8,00 & 0,00 & 0,00 & 5,00 & 1,00 & 0,20 \\
\hline Overall acceptance & 7,67 & 0,58 & 0,08 & 7,67 & 0,58 & 0,08 & 4,00 & 0,00 & 0,00 \\
\hline
\end{tabular}

\section{CONCLUSION}

It was found that the ratio of $30 \%$ white wheat and $70 \%$ rye flour is suitable for a control sample to which barley flour is added because high EC, TDS, ORP, and pH values are observed at this ratio.

It has been shown that the $30 \%$ added barley flour to a mixture of wheat and rye flour has no significant influence on the appearance and color of the bread and improves organoleptic characteristics. From white wheat, rye and barley flour, bread is obtained with very good qualities, with pleasant taste and flavor.

The results of the study show that good results are obtained in studies based on VIS spectral data. The reason for this is that the majority of the tested properties associated with flour, dough and bread are visible properties that can be analyzed in the visible spectrum of the reflected light.

Spectral indexes obtained in the $620 \mathrm{~nm}$ range were found to be a suitable tool for the analysis of rye-wheat bread with added barley flour.

Further research is needed to make changes in the breadth of the bread in the NIR spectrum of the reflected light.

\section{ACCNOWLEDGEMENTS}

The research in the current work is supported under the scientific project 10. UP/ 2018 "Safety of children's foods and healthy nutrition of adolescents - problem analysis and assessment of the available risks in the Stara Zagora region" at Trakia University of Stara Zagora, Bulgaria.

\section{APPENDIX 1. DIGITAL IMAGES AND SPECTRAL CHARACTERISTICS OF FLOUR, DOUGH AND BREAD FROM A MIXTURE OF WHITE WHEAT, RYE AND BARLEY FLOUR}

Figure 5 shows digital visual images of samples of wheat flour and rye flour mixtures in a VIS spectral region. There are visible differences in images in the VIS area.

Figure 6 shows digital visual images of samples of white wheat, rye and barley flour mixtures in VIS spectral region. As with the blend of white wheat and rye flour, there are visible differences in images in the VIS area.

Figure 7 shows visual images of dough obtained with mixtures of white wheat, rye and barley flour.

Figure 8 shows the spectral characteristics of a mixture of white wheat, rye and barley flour. The spectral characteristics of dough and bread from this mixture are also shown. 


\section{IRTTE Ipplied Researleches in Technics, Technologies and Eductation Journal of the Faculty of Technics and Technologies, Trakia University https://sites.google.com/a/trakia-uni.bg/artte/}

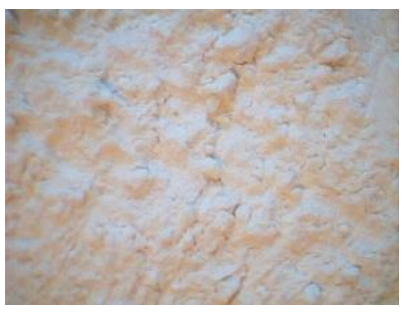

VIS, $100 \%$ wheat $+0 \%$ rye



VIS, $50 \%$ wheat $+50 \%$ rye

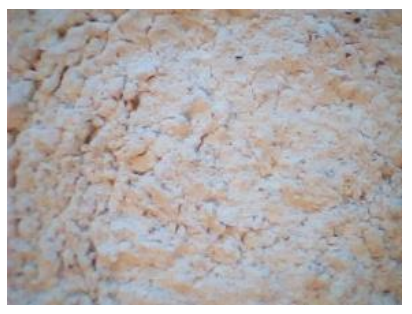

VIS, $90 \%$ wheat $+10 \%$ rye

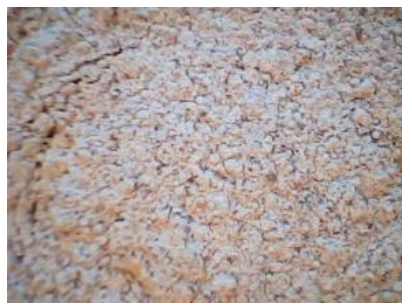

VIS, $25 \%$ wheat $+75 \%$ rye

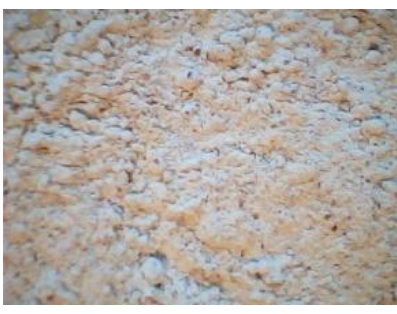

VIS, $75 \%$ wheat+25\% rye

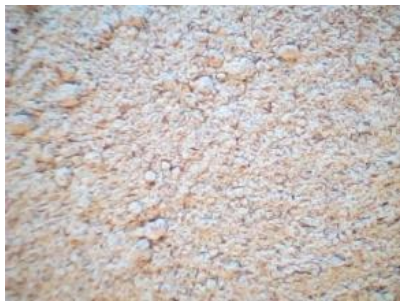

VIS, $0 \%$ wheat $+100 \%$ rye

Figure 5.

Samples of flour mixtures of white wheat and rye flour



VIS, 30W $+70 \mathrm{R}+0 \mathrm{~B}$

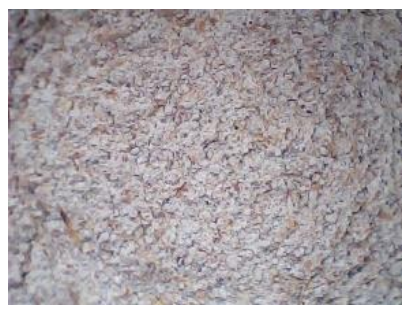

VIS, $20 \mathrm{~W}+30 \mathrm{R}+50 \mathrm{~B}$

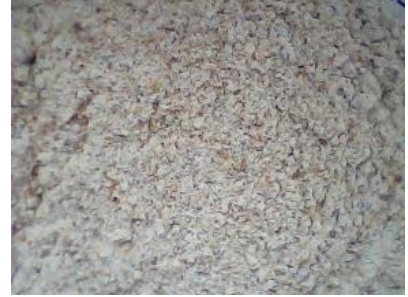

VIS, $27 \mathrm{~W}+63 \mathrm{R}+10 \mathrm{~B}$

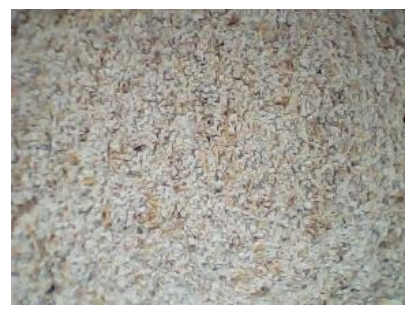

VIS, $8 \mathrm{~W}+18 \mathrm{R}+75 \mathrm{~B}$

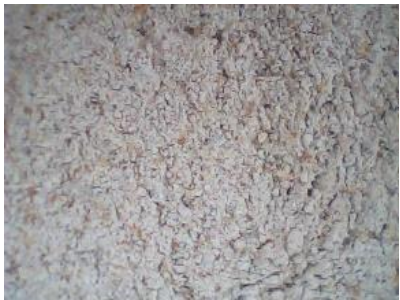

VIS, $25 \mathrm{~W}+45 \mathrm{R}+25 \mathrm{~B}$

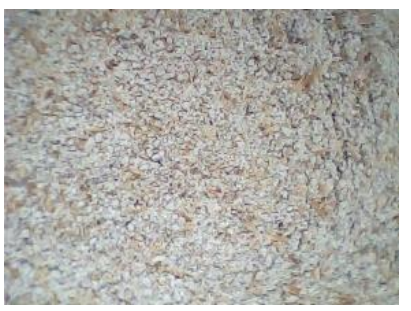

VIS, $0 \mathrm{~W}+0 \mathrm{R}+100 \mathrm{~B}$

Figure 6.

Samples of flour mixtures of white wheat, rye and barley flour 


\section{ARTITE}

Ipplied Researleches in Technics, Technologies and Eductation Journal of the Faculty of Technics and Technologies, Trakia University https://sites.google.com/a/trakia-uni.bg/artte/

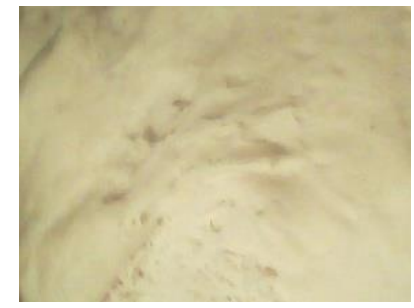

VIS, $100 \%$ wheat

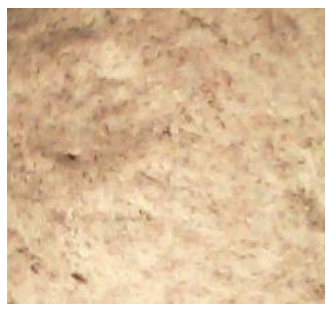

VIS, $30 \%$ wheat + $70 \%$ rye

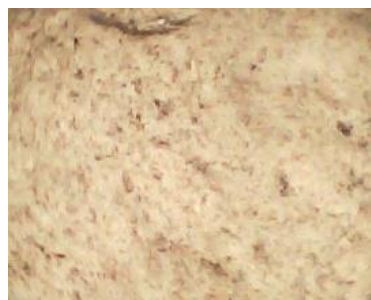

VIS, $25 \%$ wheat + $45 \%$ rye $+30 \%$ barley

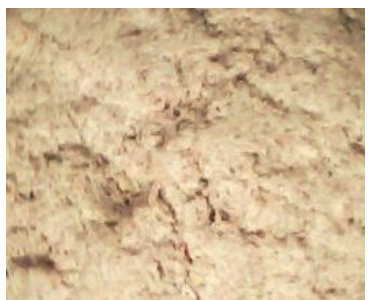

VIS, $20 \%$ wheat + $30 \%$ rye $+50 \%$ barley

Figure 7. Dough obtained from mixtures of white wheat, rye and barley flour



a) a mixture of white wheat and rye flour

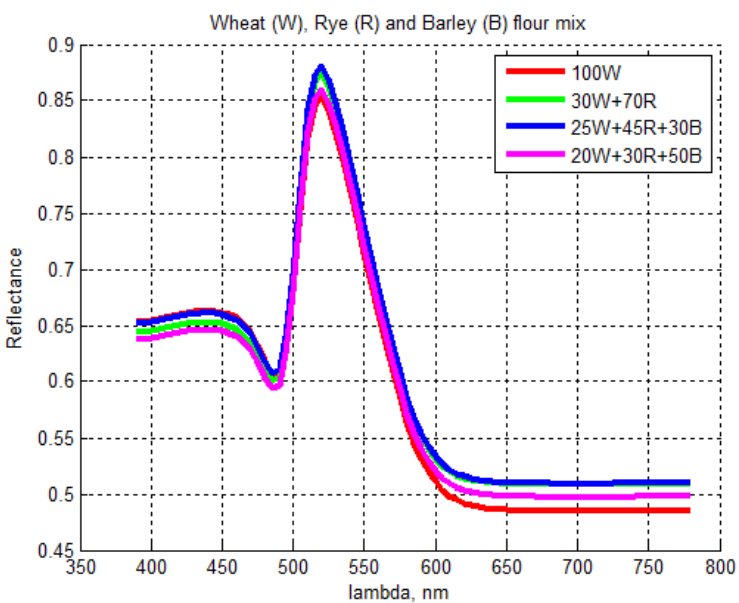

c) dough form a mixture of white wheat, rye and barley flour



b) a mixture of white wheat, rye and barley flour



d) bread from a mixture of white wheat, rye and barley flour

Figure 8. Spectral characteristics

IRTIIE Vol. 7, No. 1, 2019 ISSN 1314-8788 (print), ISSN 1314-8796 (online), doi: 10.15547/artte.2019.01.004 


\section{REFERENCES}

[1] Approved standard. (2011). "Bulgaria", "White bread", No 02/2011. (in Bulgarian).

[2] Bastin S. (2010). Types of Flour Used in Baking. FN-SSB.921, University of Kentucky, College of Agriculture, pp. 1-2.

[3] Baycheva, S. (2016). Application of devices of measurement of color in analysis of food products. Innovation and entrepreneurship, Vol.4, No.4, pp. 43-59.

[4] Dimov I., N. Petkova, G., Nakov, I. Taneva, I. Ivanov, V. Stamatovska. (2018). Improvement of antioxidant potential of wheat flours and breads by addition of medicinal plants. Ukrainian food journal, Vol. 7, No. 4, pp. 671-681.

[5] Glassner A. (1989). How to derive a spectrum from an RGB triplet. IEEE Computer Graphics and Applications 9, 4 (July 1989), pp. 95-99.

[6] Kalnina S., T. Rakcejeva, D. Kunkulberga. (2015). Rheological properties of whole grain wheat, rye and hull-less barley flour blends for pasta production. Food sciences Research for Rural Development, Vol. 1, pp. 150-156.

[7] Kumar S. (2017). Consumers Buying Behaviour - A Diagnostic Study. Ushus-Journal of Business Management, Vol. 16, No. 4, pp. 1-13.

[8] Lahouar L., A. el Arem, L. Achour. (2016). Bioactive compounds in whole grain barley: Nutraceutical properties and health benefits. Journal of Bioresources Valorization, Vol. 1, No. 1, pp. 5-15.

[9] Mihalkova N., S. Ivanova, G. Marinova, V. Batchvarov, P. Parvanova. (2015). Method for Obtaining of Bread From a Flour Mixture of Wheat, Oats, Rye, Barley and Triticale. Plant science, Vol. LII, No. 5, pp. 60-65.

[10] Mihalkova N., S. Ivanova, L. Angelov. (2014). Obtaining the bread with healthy ingredients - a mixture of rye, oat and wheat flour. Journal of Mountain Agriculture on the Balkans, Vol. 17, No. 5, pp. 1200-1219.

[11] Mladenov M. (2015). Complex assessment of the quality of food products by visual image analysis, spectrophotometric and hyper-spectral characteristics. Monograph. University Publishing Center of Rousse University "A. Kanchev", Rousse, 2015. (in Bulgarian).

[12] Ordinance No. 9/ 2001 on the quality of water intended for drinking and household purposes regulation on requirements for the labeling and presentation of food. (in Bulgarian).

[13] Ordinance on the requirements for the composition and characteristics of the salt for food purposes adopted by Decree № 23/2001. (in Bulgarian);

[14] $\mathrm{pH}$ Also known as measure of Acidity and Alkalinity. http://bakerpedia.com/processes/ph/ (available on 01.02.2018).

[15] Spectral and XYZ Color Functions. https://www.mathworks.com/ (available on 12.11.2017).

[16] Tsenov N., I. Stoeva, K. Kostov, I. Panayotov, I. Todorov, T. Petrova, P., I. Iliev, V. Kiryakova. (2009). Characterization of wheat cultivar Slaveya. Plant Sciences, Vol. 46, No. 5, pp. 468-474. (in Bulgarian).

[17] Vilaseca M., J. Pujol, M. Arjona, F. Martínez-Verdú. (2004). Color visualization system for near-infrared multispectral images. Proceedings of The Second European Conference on Colour Graphics, Imaging and Vision CGIV 2004, pp. 431-436.

[18] Zadeh A., F. Veroustraete, J. Buytaert, J. Dirckx, R. Samson. (2013). Assessing urban habitat quality using spectral characteristics of Tilia leaves. Environmental Pollution, Vol. 178, pp. 7-14.

[19] Zlateva D., G. Karadzhov. (2011). A study on the effect of the flour type and some additives on the staling of bread. Izvestiya - Journal of University of Economics of Varna, No. 1, pp. 61-72.

IRTIIE Vol. 7, No. 1, 2019 ISSN 1314-8788 (print), ISSN 1314-8796 (online), doi: 10.15547/artte.2019.01.004 